Int. J. Electrochem. Sci., 14 (2019) 2277 - 2289

\title{
Influence of Cerium and Tungsten Addition on the Passive Behaviour of 444-type Ferritic Stainless Steels
}

\author{
Ming-yu Ma ${ }^{1}$, Chun-lin He ${ }^{2}$ Hou-long Liu ${ }^{1}$, Li-qing Chen ${ }^{1, *}$ \\ 1 State Key Laboratory of Rolling and Automation, Northeastern University, Shenyang 110819, China \\ 2 College of Mechanical Engineering, Shenyang University, Shenyang 110044, China \\ *E-mail: lqchen@mail.neu.edu.cn
}

doi: $10.20964 / 2019.03 .31$

Received: 3 September 2018 / Accepted: 17 October 2018 / Published: 7 February 2019

\begin{abstract}
The surface passivity properties of conventional 444-type ferritic stainless steel (FSS), Ce-containing 444-type FSS and W-Ce-containing 444-type FSS were studied in a $1.0 \mathrm{~mol} / \mathrm{L} \mathrm{H}_{2} \mathrm{SO}_{4}+0.5 \mathrm{~mol} / \mathrm{L} \mathrm{NaCl}$ solution by employing electrochemical impedance spectroscopy (EIS) analysis, the potentiodynamic polarization test and capacitance measurement. The potentiodynamic polarization curves revealed that the $\mathrm{Ce}$ and/or $\mathrm{W}$ addition did not affect the pitting potential $E_{\mathrm{p}}$ and the corrosion potential $E_{\text {corr }}$, whereas the corrosion current density $i_{\text {corr }}$ and the passive current density $i_{\mathrm{p}}$ were decreased significantly. The morphological observation of the specimens after polarization suggested that alloying with $\mathrm{Ce}$ and $\mathrm{W}$ decreased the number of pitting sites and inhibited the active dissolution of pits. The Mott-Schottky analysis revealed that all the oxide layers formed on FSS behaved as n-type semiconductors at the potential range of $0.3-0.8 \mathrm{~V}_{\mathrm{SCE}}$ and that the donor concentration $N_{\mathrm{D}}$ in the passive film increased with $\mathrm{Ce}$ and $\mathrm{W}$ alloying. In addition, the diffusivity values of the donors in FSS passive films were calculated based on the combination of capacitance measurements and PDM theory. The EIS analysis showed that the $\mathrm{Ce}-\mathrm{W}$-containing stainless steel presented lower polarization resistance values.
\end{abstract}

Keywords: Ferritic stainless steel; Tungsten; Cerium; Passive film; Diffusivity.

\section{$\underline{\text { FULL TEXT }}$}

(C) 2019 The Authors. Published by ESG (www.electrochemsci.org). This article is an open access article distributed under the terms and conditions of the Creative Commons Attribution license (http://creativecommons.org/licenses/by/4.0/). 